\title{
Low Vitamin D Status Is Not Associated With Thyroid Cancer Risk
}

\author{
Dohee Kim
}

\begin{abstract}
Background: Low vitamin D status has been known to be associated with the increased prevalence and worse prognosis of several cancers. The aim of this study was to investigate the correlation between vitamin D insufficiency and the risk of malignancy of thyroid nodules and the prognosis of differentiated thyroid cancers (DTCs).

Methods: This cross-sectional study included a total of 410 patients who submitted to simultaneous measurements of serum 25-hydoxyvitamin D (25(OH)D) and ultrasonography-guided fine-needle aspiration for thyroid nodules during the period from March 2005 to June 2009. Levels of serum free thyroxine, thyroid stimulating hormone, anti-thyroid antibodies, parathyroid hormone (PTH), calcium, and phosphorus were also measured. Vitamin D insufficiency was defined as a serum $25(\mathrm{OH}) \mathrm{D}$ level $<75 \mathrm{nmol} / \mathrm{L}$. In addition, the clinicopathologic characteristics of 34 patients who underwent thyroidectomy for DTC were analyzed retrospectively.
\end{abstract}

Results: The prevalence of vitamin D insufficiency was $40.2 \%$. Serum $25(\mathrm{OH}) \mathrm{D}$ levels and the prevalence of vitamin D insufficiency showed no significant differences between benign $(\mathrm{n}=366)$ and malignant $(n=44,10.7 \%)$ thyroid nodules. Serum 25(OH)D levels showed a negative correlation only with serum PTH levels after adjusting for age, sex, body mass index, and sampling season. Among DTC patients, vitamin D insufficiency was not associated with disease stage or any other prognostic features.

Conclusions: Vitamin D insufficiency was not associated with the development of thyroid cancer or the prognostic characteristics of DTC.

Keywords: Thyroid cancer; Thyroid nodule; Vitamin D; Deficiency

\section{Introduction}

The main role of vitamin $\mathrm{D}$ is to maintain calcium and phos-

Manuscript accepted for publication August 16, 2016

Division of Endocrinology, Department of Internal Medicine, Dankook University College of Medicine; Department of Kinesiologic Medical Science, Graduate, Dankook University, Cheonan 330-714, Korea.

Email: dh9070@hanmail.net

doi: http://dx.doi.org/10.14740/jem365w phorus homeostasis, thus maintaining bone health [1]. Recent evidence has demonstrated that vitamin D deficiency, which is really common worldwide, could also be associated with non-skeletal actions including cancers, autoimmune diseases, metabolic syndrome, cardiovascular disorders, and infectious diseases, as well as all-cause mortality [2-4]. Moreover, vitamin D directly or indirectly controls more than 200 genes, including genes responsible for the regulation of cellular proliferation, differentiation, apoptosis, and angiogenesis, thus decreasing the cellular proliferation of both normal cells and cancer cells and inducing their terminal differentiation [3]. Epidemiological studies suggest that vitamin D deficiency is associated with increased incidence of cancer and worse outcomes, especially colon, breast, and prostate cancers, although many studies do not demonstrate these associations $[5,6]$. In a recent review, the overall results of observational studies of the relationship between 25-hydroxyvitamin D $(25(\mathrm{OH}) \mathrm{D})$, a biomarker of vitamin D status, and colorectal cancer revealed a consistent inverse association for incidence and mortality. For breast cancer, results have generally demonstrated a relationship between higher 25(OH)D levels and lower risk for progression and mortality [6]. In contrast, randomized, double-blind clinical trials conducted to date have generally failed to support these findings [6]. For prostate cancer, there is no convincing evidence of an association between 25(OH)D and incidence, and inconsistent data for progression and mortality, although the results of one open-label clinical trial suggest that supplementation with 4,000 IU/day of vitamin D may inhibit progression of the disease [6]. Multiple experimental studies of cancer support a role for dietary vitamin D and calcitriol in retarding cancer development and progression; however, data from human clinical trials are far inconsistent [5].

Thyroid cancer is the most common endocrine malignancy, with rising incidence $[7,8]$. The vitamin $\mathrm{D}$ receptor (VDR) is expressed in thyroid cancer tissue as well as normal thyroid tissue $[8,9]$. VDR, 1 $\alpha$-hydroxylase (CYP27B1), and 24-hydroxylase (CYP24A1) expression levels are increased in benign and malignant differentiated thyroid tumors as compared with normal thyroid, but a decrease or complete loss of expression was observed for local nodal and especially distant metastasis or anaplastic thyroid cancer, suggesting a local antitumor response of $1,25(\mathrm{OH})_{2} \mathrm{D}$ in early-stage cancer [8-10]. In agreement with experimental studies in other cancer types, the exposure of a variety of thyroid cancer cells to vitamin D and synthetic vitamin $\mathrm{D}$ analogues in vitro leads to the manifestation of anti-proliferative and pro-differentiation properties. These results have been confirmed by in vivo studies [7, 8]. A few epidemiological studies support an inverse relationship 
between thyroid cancer incidence or higher proliferation values and latitude, although vitamin D levels were not measured [7]. For studies estimating vitamin D consumption and thyroid cancer risk, no convincing associations have been shown, maybe due to the general poor correlation between vitamin D deficiency and estimates of vitamin D consumption [7]. Several reports indicate no significant differences in vitamin D status between thyroid cancer patients and controls [11-14], while other groups reported the association of low serum $25(\mathrm{OH}) \mathrm{D}$ or $1,25(\mathrm{OH})_{2} \mathrm{D}$ levels and the incidence of thyroid cancer or poor clinicopathologic characteristics [13, 15-17]. Based on the anti-proliferative and pro-differentiating effects of vitamin $\mathrm{D}$, the aim of this study was to examine serum $25(\mathrm{OH}) \mathrm{D}$ levels in patients with thyroid nodules and to investigate the correlation between low vitamin D status and the incidence of thyroid cancer and poor clinicopathologic characteristics.

\section{Patients and Methods}

\section{Patients}

The medical records of patients who visited the Endocrinology Outpatient Clinic of Dankook University Hospital for the evaluation of thyroid nodules by one endocrinologist from March 2005 to June 2009 were reviewed. Patients who were tested for serum $25(\mathrm{OH}) \mathrm{D}$, free thyroxine (T4), thyroid stimulating hormone (TSH), and anti-thyroid antibodies, as well as simultaneously examined by thyroid ultrasonography (US)-guided fine-needle aspiration (FNA), were considered for inclusion criteria. The antibodies were thyroid peroxidase antibody (TPO-Ab) and thyroglobulin antibody (Tg-Ab), suggesting autoimmune thyroid disease such as Hashimoto's thyroiditis. Serum parathyroid hormone (PTH), calcium, albumin, and phosphorus were additionally measured in these patients. Patients with metabolic bone diseases, primary hyperparathyroidism, renal disorders, liver disorders or epilepsy treated by anticonvulsants, or on other medications that might alter vitamin D metabolism (including calcium and vitamin D supplementation) were excluded.

A total of 498 patients who submitted to simultaneous measurements of serum $25(\mathrm{OH}) \mathrm{D}$ and US-guided FNA were initially reviewed, and 67 patients with diseases or medications affecting vitamin D metabolism or with postoperative blood sampling were excluded. For a nodule with a non-diagnostic or unsatisfactory cytology result, US-guided FNA was repeated. Patients with malignancies, lesions suspicious for malignancy, follicular neoplasms, or atypia of undetermined significance or follicular lesions of undetermined significance (AUS/FLUS) on US-guided FNA underwent thyroidectomy within 1 - 2 months after US-guided FNA. All lesions were then confirmed as malignant or benign. Additionally, 21 subjects who had thyroid nodules with AUS/FLUS on US-guided FNA but were follow-up loss or transferred to other hospital were excluded. Finally, a total of 410 patients were enrolled and diagnosed with benign $(n=366)$ and malignant $(n=44$, $10.7 \%$ ) thyroid nodules. Among 44 subjects with malignant thyroid nodules, a patient with medullary thyroid cancer af- ter surgery and nine patients with all papillary thyroid cancer (PTC) on cytology who were transferred to other hospital for surgery or refused to surgery were excluded. Finally, 34 differentiated thyroid cancer (DTC) patients (papillary $(\mathrm{n}=33)$, follicular $(n=1)$ ) were additionally evaluated with regard to their clinicopathologic characteristics after thyroid surgery. For the stage of DTC, American Joint Committee on Cancer (AJCC) 7th edition/TNM classification system was used [18]. This study was approved by the Institutional Review Board of Dankook University Hospital.

\section{Laboratory measurements}

Serum concentrations of $25(\mathrm{OH}) \mathrm{D}$ were obtained using a Roche Modular E170 analyzer in combination with an electrochemiluminescence immunoassay (ECLIA; Roche Diagnostics $^{\circledR}$, Penzberg, Germany). Although debatable, vitamin D deficiency is defined as a $25(\mathrm{OH}) \mathrm{D}$ level $<50 \mathrm{nmol} / \mathrm{L}$, vitamin D insufficiency as a $25(\mathrm{OH}) \mathrm{D}$ level of $50-72.5 \mathrm{nmol} / \mathrm{L}$, and sufficiency as a $25(\mathrm{OH}) \mathrm{D}$ level $\geq 75 \mathrm{nmol} / \mathrm{L}$ [3]. The cut-off value for vitamin D insufficiency was defined as serum $25(\mathrm{OH}) \mathrm{D}$ levels $<75 \mathrm{nmol} / \mathrm{L}$ in this study. Seasonal differences were defined by the laboratory sampling date, and categorized into four seasons: spring, March to May; summer, June to August; autumn, September to November; winter, December to February. Serum free T4 and TSH were measured using a fT4-CTX radioimmunoassay (RIA) kit (Diasorin, Saluggia, Italy) and an RIA-gnost ${ }^{\circledR}$ hTSH kit (Cisbio Bioassays, Codolet, France), respectively. Serum TPO-Ab and $\mathrm{Tg}-\mathrm{Ab}$ were measured with a TM Ab immunoradiometric assay (IRMA) CT kit (RADIM, Pomezia, Italy) and a Tg-Ab one step CT RIA kit (RADIM), respectively. The reference ranges for thyroid assays were serum free T4 10.04 - $24.97 \mathrm{pmol} / \mathrm{L}$, TSH 0.25 - $4.0 \mathrm{mIU} / \mathrm{L}$, TPO-Ab 0 - 100 mIU/L, and Tg-Ab 0 - 70 mIU/L. Serum PTH levels were assessed by a total intact PTH IRMA kit (IBL International GMBH, Hamburg, Germany) (normal, 10 - 65 ng/L). Serum calcium, albumin, and phosphorus were measured using a model TBA-200FR instrument (Toshiba Medical System, Tokyo, Japan). Corrected calcium levels were calculated on the basis of albumin levels.

All US examinations were performed using one of two US instruments: an iU22 (Philips Medical Systems, Bothell, WA, USA) or an Acuson Sequoia 512 (Siemens Medical Solutions, Mountain View, CA, USA) equipped with a linear high frequency probe $(4-15 \mathrm{MHz}$ ) by experienced radiologists.

\section{Statistical analysis}

All analyses were performed using SPSS software version 23.0 (SPSS, Chicago, IL, USA). Comparison of categorical variables between groups was done using Pearson's Chi-square test or Fisher's exact test. Cochran-Mantel-Haenszel test was additionally used for the odds ratio after control of covariates such as age, sex, body mass index (BMI), and season. Continuous variables are expressed as mean \pm standard deviation. Student's $t$-test was used for the comparison of continuous 
Table 1. Baseline Characteristics Divided by Benign or Malignant Thyroid Nodules

\begin{tabular}{|c|c|c|c|c|}
\hline & Total $(n=410)$ & Benign $(n=366)$ & Malignant $(n=44)$ & P value $^{\mathrm{a}}$ \\
\hline Age, years & $48.2 \pm 13.1$ & $48.1 \pm 13.3$ & $48.7 \pm 11.4$ & 0.805 \\
\hline Sex, male, n $(\%)$ & $57 / 410(13.9 \%)$ & $54 / 366(14.8 \%)$ & $3 / 44(6.8 \%)$ & 0.173 \\
\hline BMI, $\mathrm{kg} / \mathrm{m}^{2}$ & $24.0 \pm 3.6$ & $23.9 \pm 3.6$ & $24.6 \pm 3.6$ & 0.212 \\
\hline $25(\mathrm{OH}) \mathrm{D}, \mathrm{nmol} / \mathrm{L}$ & $99.3 \pm 57.4$ & $99.1 \pm 55.7$ & $102.3 \pm 48.7$ & 0.707 \\
\hline Prevalence of vitamin D insufficiency ${ }^{b}, \mathrm{n}(\%)$ & $165 / 410(40.2 \%)$ & $148 / 366(40.4 \%)$ & $17 / 44(38.6 \%)$ & 0.486 \\
\hline PTH, ng/L & $30.4 \pm 16.5$ & $30.3 \pm 17.0$ & $31.3 \pm 12.4$ & 0.697 \\
\hline Calcium $^{\mathrm{c}}, \mathrm{mmol} / \mathrm{L}$ & $2.28 \pm 0.11$ & $2.29 \pm 0.10$ & $2.25 \pm 0.16$ & 0.172 \\
\hline Phosphorous, mmol/L & $1.22 \pm 0.18$ & $1.21 \pm 0.18$ & $1.27 \pm 0.20$ & 0.098 \\
\hline Free $\mathrm{T} 4, \mathrm{pmol} / \mathrm{L}$ & $16.47 \pm 5.66$ & $16.47 \pm 5.92$ & $16.09 \pm 3.09$ & 0.619 \\
\hline $\mathrm{TSH}, \mathrm{mIU} / \mathrm{L}$ & $2.96 \pm 6.45$ & $3.08 \pm 6.79$ & $1.95 \pm 1.80$ & 0.276 \\
\hline TPO-Ab, mIU/L & $120.91 \pm 401.69$ & $128.66 \pm 420.77 *$ & $54.29 \pm 149.89 *$ & $0.022^{*}$ \\
\hline $\mathrm{Tg}-\mathrm{Ab}, \mathrm{mIU} / \mathrm{L}$ & $129.89 \pm 364.72$ & $132.09 \pm 364.20$ & $111.44 \pm 372.95$ & 0.726 \\
\hline Positivity of TPO-Ab, n (\%) & $63 / 403(15.4 \%)$ & 60/361 (16.6\%) & $3 / 42(7.1 \%)$ & 0.121 \\
\hline Positivity of Tg-Ab, n (\%) & $95 / 404(23.5 \%)$ & $88 / 361(24.4 \%)$ & $7 / 43(16.3 \%)$ & 0.237 \\
\hline Positivity of TPO-Ab or Tg-Ab, n (\%) & $110 / 405(27.2 \%)$ & $102 / 362(28.2 \%)$ & $8 / 43(18.6 \%)$ & 0.182 \\
\hline
\end{tabular}

Data were mean \pm standard deviation or numbers (\%). ap values were based on comparisons between benign and malignant thyroid nodule groups. bVitamin D insufficiency was defined as serum $25(\mathrm{OH}) \mathrm{D}$ levels $<75 \mathrm{nmol} / \mathrm{L}$. ${ }^{\mathrm{c} C a l c i u m}$ levels were corrected calcium levels calculated on the basis of albumin levels. * $\mathrm{P}<0.05$. BMI: body mass index; 25(OH)D: 25-hydroxyvitamin D; PTH: parathyroid hormone; free T4; free thyroxine; TSH: thyroid stimulating hormone; TPO-Ab: thyroid peroxidase antibody; Tg-Ab: thyroglobulin antibody.

variables between two groups. One-way ANOVA was used for the comparison of continuous variables among three or more groups. Then, the Tukey method was used for multiple comparisons. A logistic regression modeling was used to evaluate the effects of vitamin D insufficiency on the risk of malignancy and the clinicopathologic parameters in DTC. Pearson's correlation analysis was performed to examine the correlation between vitamin D levels and biochemical variables including age, BMI, serum PTH, calcium, phosphorus, fT4, TSH, and anti-thyroid antibody levels, and tumor size. All P-values were two-sided, and $\mathrm{P}<0.05$ was considered statistically significant for all tests.

\section{Results}

A total of 410 subjects (353 females (86.1\%) and 57 males $(13.9 \%)$ ) were evaluated (Table 1$)$. The mean age was $48.2 \pm$ 13.1 years and the mean BMI was $24.0 \pm 3.6 \mathrm{~kg} / \mathrm{m}^{2}$. The overall mean serum 25(OH)D level was $99.3 \pm 57.4 \mathrm{nmol} / \mathrm{L}$. The prevalence of vitamin D insufficiency was $40.2 \%$. The vitamin $\mathrm{D}$ status in each season of blood collection differed significantly $(\mathrm{P}<0.001)$, and serum $25(\mathrm{OH}) \mathrm{D}$ levels in autumn $(\mathrm{n}=$ $96,123.3 \pm 50.9 \mathrm{nmol} / \mathrm{L})$ were significantly higher $(\mathrm{P}<0.001$ vs. spring and winter, and $\mathrm{P}=0.014$ vs. summer) than in spring $(\mathrm{n}=153,94.1 \pm 62.4 \mathrm{nmol} / \mathrm{L})$, winter $(\mathrm{n}=85,62.6 \pm 42.7$ $\mathrm{nmol} / \mathrm{L})$, and summer $(\mathrm{n}=76,98.6 \pm 45.7 \mathrm{nmol} / \mathrm{L})$.

A comparison of benign $(n=366)$ and malignant $(n=44)$ thyroid nodules in terms of clinical characteristics is presented in Table 1. The serum 25(OH)D levels and the prevalence of vitamin $\mathrm{D}$ insufficiency between benign and malignant groups showed no significant differences $(99.1 \pm 55.7 \mathrm{nmo} / \mathrm{L}$ vs. 102.3 $\pm 48.7 \mathrm{nmol} / \mathrm{L}, 40.4 \%$ vs. $38.6 \%$, respectively). Vitamin D insufficiency also did not increase the risk of malignancy in subgroup analysis: sex, season, age ( $<45$ vs. $\geq 45$ years), and BMI $\left(<25\right.$ vs. $\geq 25 \mathrm{~kg} / \mathrm{m}^{2}$ or $<30 \mathrm{vs}$. $\left.\geq 30 \mathrm{~kg} / \mathrm{m}^{2}\right)$. Age, sex, BMI, and serum calcium, phosphorus, PTH, free T4, and TSH levels were not significantly different between groups. The serum TPO-Ab levels in patients with benign thyroid nodules were significantly higher than in those with malignant thyroid nodules $(\mathrm{P}=0.022)$, but there were no differences in serum Tg-Ab titers and prevalence of TPO-Ab or Tg-Ab positivity.

The clinical characteristics of the vitamin D insufficiency $(25(\mathrm{OH}) \mathrm{D}<75 \mathrm{nmol} / \mathrm{L})$ and vitamin D sufficiency $(25(\mathrm{OH}) \mathrm{D}$ $\geq 75 \mathrm{nmol} / \mathrm{L}$ ) groups are compared in Table 2 . Patients with vitamin D insufficiency $(n=165)$ were significantly younger and more predominantly female, and had lower BMI than in those with vitamin D sufficiency. The serum PTH levels in patients with vitamin D insufficiency were significantly higher than in those with vitamin D sufficiency, but there were no differences in serum calcium, phosphorus, free T4, TSH, TPO-Ab, and $\mathrm{Tg}-\mathrm{Ab}$ levels and the prevalence of TPO-Ab or Tg-Ab positivity, as well as the prevalence of malignancy. When the correlations between serum 25(OH)D levels and age, BMI, serum PTH, calcium, phosphorus, free T4, TSH, TPO-Ab, and Tg-Ab levels were analyzed, serum $25(\mathrm{OH}) \mathrm{D}$ levels showed positive correlations with BMI $(\mathrm{r}=0.157, \mathrm{P}=0.002)$, and negative correlations with serum PTH $(r=-0.168, \mathrm{P}=0.001)$. However, serum 25(OH)D levels showed negative correlations only with serum PTH levels after adjusted for age, sex, BMI, and season $(\mathrm{r}=-0.164, \mathrm{P}=0.009)$.

In addition, 34 DTC patients who were informed about 
Table 2. Baseline Characteristics of Thyroid Nodules According to the Presence of Vitamin D Insufficiency

\begin{tabular}{|c|c|c|c|}
\hline & $\begin{array}{l}\text { Vitamin D insufficiency }(25(\mathrm{OH}) \\
D<75 \mathrm{nmol} / \mathrm{L})(\mathrm{n}=165)\end{array}$ & $\begin{array}{l}\text { Vitamin D sufficiency }(25(\mathrm{OH}) \\
D \geq 75 \mathrm{nmol} / \mathrm{L})(\mathrm{n}=\mathbf{2 4 5})\end{array}$ & P value \\
\hline Age, years* & $46.5 \pm 14.4^{*}$ & $49.3 \pm 12.0^{*}$ & $0.038^{*}$ \\
\hline Sex, male, $\mathrm{n}(\%)^{*}$ & $13 / 165(7.9 \%)^{*}$ & $44 / 245(18.0 \%)^{*}$ & $0.004 *$ \\
\hline BMI, $\mathrm{kg} / \mathrm{m}^{2 *}$ & $23.1 \pm 3.3^{*}$ & $24.5 \pm 3.8^{*}$ & $0.000 *$ \\
\hline $25(\mathrm{OH}) \mathrm{D}, \mathrm{nmol} / \mathrm{L}^{*}$ & $54.91 \pm 14.23 *$ & $129.29 \pm 51.67 *$ & $0.000 *$ \\
\hline PTH, ng/L* & $33.9 \pm 20.3^{*}$ & $28.1 \pm 13.0^{*}$ & $0.001^{*}$ \\
\hline Calcium, mmol/L & $2.29 \pm 0.10$ & $2.28 \pm 0.11$ & 0.643 \\
\hline Phosphorous, mmol/L & $1.23 \pm 0.16$ & $1.22 \pm 0.19$ & 0.635 \\
\hline Free T4, pmol/L & $16.47 \pm 5.66$ & $16.47 \pm 5.66$ & 0.859 \\
\hline TSH, mIU/L & $3.32 \pm 7.94$ & $2.71 \pm 5.23$ & 0.350 \\
\hline $\mathrm{TPO}-\mathrm{Ab}, \mathrm{mIU} / \mathrm{L}$ & $152.91 \pm 490.59$ & $99.39 \pm 328.11$ & 0.224 \\
\hline $\mathrm{Tg}-\mathrm{Ab}, \mathrm{mIU} / \mathrm{L}$ & $177.65 \pm 468.59$ & $97.92 \pm 270.57$ & 0.051 \\
\hline Positivity of TPO-Ab, n (\%) & $30 / 162(18.5 \%)$ & $33 / 241(13.7 \%)$ & 0.191 \\
\hline Positivity of Tg-Ab, n (\%) & $42 / 162(25.9 \%)$ & $53 / 242(21.9 \%)$ & 0.350 \\
\hline Positivity of TPO-Ab or Tg-Ab, n (\%) & $51 / 162(31.5 \%)$ & $59 / 243(24.3 \%)$ & 0.110 \\
\hline Prevalence of malignancy, n (\%) & $17 / 165(10.3 \%)$ & $27 / 245(11.0 \%)$ & 0.818 \\
\hline
\end{tabular}

Data were mean \pm standard deviation or numbers (\%). Calcium levels were corrected calcium levels calculated on the basis of albumin levels. ${ }^{*} \mathrm{P}<$ 0.05. BMI: body mass index; 25(OH)D: 25-hydroxyvitamin D; PTH: parathyroid hormone; free T4: free thyroxine; TSH: thyroid stimulating hormone; TPO-Ab: thyroid peroxidase antibody; Tg-Ab: thyroglobulin antibody..

clinicopathologic characteristics after thyroid surgery were analyzed. Of these, 31 patients were female and histologic types of thyroid cancers were papillary $(\mathrm{n}=33)$ (conventional $(\mathrm{n}=$ $30)$, solid variant $(n=1)$, oncocytic variant $(n=1)$, diffuse sclerosing variant $(\mathrm{n}=1))$ and follicular $(\mathrm{n}=1)$. The mean age at diagnosis was $49.2 \pm 10.9$ years and the mean BMI was $24.6 \pm 3.6 \mathrm{~kg} / \mathrm{m}^{2}$. The overall mean serum 25(OH)D level was $104.6 \pm 49.4 \mathrm{nmol} / \mathrm{L}$, and the prevalence of vitamin D insufficiency was $35.3 \%$. The resected primary tumors were $1.54 \pm 1.30 \mathrm{~cm}$ in size. Nine patients $(26.5 \%)$ had multifocal tumors, 14 patients $(41.2 \%)$ had extrathyroidal invasion, and one patient $(2.9 \%)$ had lymphovascular invasion. Nine patients $(26.5 \%)$ had cervical lymph node metastasis, but none had distant metastasis. The AJCC/TNM stage was as follows: 23 patients $(67.6 \%)$ for stage I, two patients $(5.9 \%)$ for stage II, and nine patients $(26.5 \%)$ for stage III. Two patients $(5.9 \%)$ recurred in cervical lymph nodes and 12 patients $(35.3 \%)$ experienced postoperative hypocalcaemia.

Table 3 shows the clinicopathologic characteristics of 34 DTC patients in the vitamin D insufficiency $(n=12)$ and vitamin D sufficiency $(n=22)$ groups. The baseline characteristics such as age, sex, BMI and preoperative serum PTH, calcium, phosphorus, TSH, TPO-Ab, and Tg-Ab titers were not different between two groups, except that only free T4 levels in patients with vitamin D insufficiency group were significantly higher than in those with vitamin $\mathrm{D}$ sufficiency $(\mathrm{P}=0.034)$. Tumor size, multifocality, extrathyroidal invasion, lymph node metastasis, cancer stage, lymphovascular invasion, risk of recurrence, and postoperative hypocalcemia did not differ significantly according to the presence of vitamin D insufficiency. Again, the association between the vitamin D insufficiency and these prognostic parameters was not significant.

\section{Discussion}

In this study, the serum 25(OH)D levels and the prevalence of vitamin D insufficiency did not differ significantly between benign and malignant thyroid nodules. Patients with vitamin D insufficiency were significantly younger and more predominantly female, and had lower BMI and higher PTH levels than in those with vitamin D sufficiency. Serum 25(OH)D levels showed negative correlations only with serum PTH levels after adjusting for age, sex, BMI, and season. The preoperative vitamin D insufficiency was not associated with the aggressiveness or prognosis of DTC.

Several clinical studies have shown no association between vitamin D status and the incidence and worse outcomes of thyroid cancer, which is consistent with the current study. Laney et al reported that serum 25(OH)D levels and the percent with $25(\mathrm{OH}) \mathrm{D}<75 \mathrm{nmol} / \mathrm{L}$ were not different between 42 thyroid nodule, 45 thyroid cancer in remission, and 24 active thyroid cancer patients, and were not affected by cancer stage [12]. Stepien et al demonstrated that there were no significant differences when comparing serum 25(OH)D levels among individuals with multinodular goiter (34), thyroid cancer (27 papillary, 16 follicular, and seven anaplastic), and 26 healthy controls, although $1,25(\mathrm{OH})_{2} \mathrm{D}$ levels were significantly lower in thyroid cancer and advanced-stage disease [13]. Jonklaas et al found no association between preoperative 25(OH)D levels and a diagnosis of thyroid cancer, disease stage, or any other prognostic features [14]. A recent study showed that the pre- 
Table 3. Clinicopathologic Characteristics of Differentiated Thyroid Cancers According to the Presence of Vitamin D Insufficiency

\begin{tabular}{|c|c|c|c|}
\hline & $\begin{array}{l}\text { Vitamin D insufficiency }(25(\mathrm{OH}) \\
D<75 \mathrm{nmol} / \mathrm{L})(\mathrm{n}=12)\end{array}$ & $\begin{array}{l}\text { Vitamin D sufficiency }(25(\mathrm{OH}) \\
D \geq 75 \mathrm{nmol} / \mathrm{L})(\mathrm{n}=22)\end{array}$ & P value \\
\hline Age at diagnosis, years & $52.7 \pm 9.8$ & $47.4 \pm 11.2$ & 0.178 \\
\hline Sex, male, n (\%) & $0(0 \%)$ & $3(13.6 \%)$ & $0.537 *$ \\
\hline BMI, $\mathrm{kg} / \mathrm{m}^{2}$ & $23.6 \pm 3.0$ & $25.1 \pm 3.9$ & 0.249 \\
\hline $25(\mathrm{OH}) \mathrm{D}, \mathrm{nmol} / \mathrm{L} \dagger$ & $61.2 \pm 11.5 \dagger$ & $128.3 \pm 45.9 \dagger$ & $0.000 \dagger$ \\
\hline PTH, ng/L & $32.6 \pm 9.6$ & $30.7 \pm 9.5$ & 0.592 \\
\hline Calcium $^{\mathrm{a}}, \mathrm{mmol} / \mathrm{L}$ & $2.28 \pm 0.08$ & $2.21 \pm 0.20$ & 0.242 \\
\hline Phosphorus, mmol/L & $1.29 \pm 0.11$ & $1.28 \pm 0.24$ & 0.833 \\
\hline Free $\mathrm{T} 4, \mathrm{pmol} / \mathrm{L} \dagger$ & $17.63 \pm 3.99 \dagger$ & $14.80 \pm 2.06 \dagger$ & $0.034 \uparrow$ \\
\hline TSH, mIU/L & $1.52 \pm 0.85$ & $2.39 \pm 2.29$ & 0.217 \\
\hline TPO-Ab, mIU/L & $91.75 \pm 257.62$ & $23.16 \pm 20.67$ & 0.377 \\
\hline $\mathrm{Tg}-\mathrm{Ab}, \mathrm{mIU} / \mathrm{L}$ & $43.23 \pm 72.09$ & $21.05 \pm 23.37$ & 0.201 \\
\hline Positivity of TPO-Ab, n (\%) & $1 / 12(8.3 \%)$ & $0 / 20(0.0 \%)$ & $0.375^{*}$ \\
\hline Positivity of Tg-Ab, n (\%) & $2 / 12(16.7 \%)$ & $2 / 21(9.5 \%)$ & $0.610^{*}$ \\
\hline Positivity of TPO-Ab or Tg-Ab, n (\%) & $3 / 12(25.0 \%)$ & $2 / 21(9.5 \%)$ & $0.328^{*}$ \\
\hline Age at diagnosis $\geq 45$ years & $10(83.3 \%)$ & $12(54.5 \%)$ & $0.140^{*}$ \\
\hline Tumor size, $\mathrm{cm}$ & $1.6 \pm 1.3$ & $1.5 \pm 1.3$ & 0.962 \\
\hline Tumor size $>1 \mathrm{~cm}$ & $6(50.0 \%)$ & $10(45.5 \%)$ & 0.800 \\
\hline T stage $3 / 4$ & $6(50 \%)$ & $8(36.4 \%)$ & 0.440 \\
\hline Lymph node metastasis & $3(25 \%)$ & $6(27.3 \%)$ & $1.00 *$ \\
\hline Stage $^{\mathrm{b}}$ III/IV & $5(41.7 \%)$ & $4(18.2 \%)$ & $0.224 *$ \\
\hline Multifocality & $5(41.7 \%)$ & $4(18.2 \%)$ & $0.224 *$ \\
\hline Extrathyroidal extension & $6(50 \%)$ & $8(36.4 \%)$ & 0.440 \\
\hline Lymphovascular invasion & $0(0 \%)$ & $1(4.5 \%)$ & $1.00^{*}$ \\
\hline Recurrence rate & $1(8.3 \%)$ & $1(4.5 \%)$ & $1.00^{*}$ \\
\hline Postoperative hypocalcemia & $3(25.0 \%)$ & $9(40.9 \%)$ & $0.465^{*}$ \\
\hline
\end{tabular}

Data were mean \pm standard deviation or numbers (\%). *P-values were based on Fisher's exact test. ${ }^{\text {CC}}$ alcium levels were corrected calcium levels calculated on the basis of albumin levels. ${ }^{b}$ American Joint Committee on Cancer (AJCC) 7th edition/TNM classification system was used for the stage. $† P<0.05$. BMI: body mass index; 25(OH)D: 25-hydroxyvitamin D; PTH: parathyroid hormone; free T4: free thyroxine; TSH: thyroid stimulating hormone; TPO-Ab: thyroid peroxidase antibody; Tg-Ab: thyroglobulin antibody.

operative $25(\mathrm{OH}) \mathrm{D}$ levels were not associated with either aggressiveness or poor outcomes among 820 patients with PTC [19]. Furthermore, a systematic review suggested that the current evidence to support any protective or hazardous effect of vitamin D supplements on thyroid cancer development is inconclusive [20].

However, contrasting data were reported by other groups. Roskies et al demonstrated an inverse relationship between vitamin D deficiency $(25(\mathrm{OH}) \mathrm{D}$ levels $<37.5 \mathrm{nmol} / \mathrm{L})$ and the risk of DTC [15]. Sahin et al reported that serum 25(OH)D levels in 344 patients with PTC were significantly lower than in 116 controls, and vitamin D deficiency $(25(\mathrm{OH}) \mathrm{D}$ levels $<50 \mathrm{nmol} / \mathrm{L}$ ) was more frequent in PTC patients. Tumor diameter also showed a significant association with log-vitamin D [16]. Kim et al studied 548 women undergoing total thyroidectomy for PTC. Significantly lower preoperative $25(\mathrm{OH})$ $\mathrm{D}$ levels were found in patients with a tumor size $>1 \mathrm{~cm}$ or with lymph node metastasis. In addition, patients with $25(\mathrm{OH})$ D levels $<46.2 \mathrm{nmol} / \mathrm{L}$ (median) had significantly higher risk of advanced stage and lymph node metastasis after adjustment [17]. Penna-Martinez et al showed lower serum $1,25(\mathrm{OH})_{2} \mathrm{D}$ levels in 172 patients with DTC as compared to 321 controls, although there were no differences in $25(\mathrm{OH}) \mathrm{D}$ levels, and an association between VDR polymorphism and the risk of follicular thyroid cancer [21]. Later, the same authors revealed an association between low 25(OH)D and $1,25(\mathrm{OH})_{2} \mathrm{D}$ levels and DTC in patients with certain CYP24A1 haplotypes [22]. In the present study, the association of thyroid cancer and vitamin $\mathrm{D}$ deficiency using a criterion of $25(\mathrm{OH}) \mathrm{D}$ levels $<50 \mathrm{nmol} / \mathrm{L}$ was also analyzed, but there was no significant difference (data not shown).

Numerous preclinical studies have demonstrated that $1,25(\mathrm{OH})_{2} \mathrm{D}$ diminishes tumor growth through effects on cell cycle progression, apoptosis, differentiation, angiogenesis, 
invasion, and inflammation, directly or indirectly $[5,8]$. The mechanism underlying the antitumor effect of $1,25(\mathrm{OH})_{2} \mathrm{D}$ on thyroid cancers was mainly the result of inhibited proliferation, although the effects of redifferentiation and apoptosis were not consistent [8]. 1,25(OH) $)_{2} \mathrm{D}$ was shown to inhibit proliferation through c-mac mRNA inhibition, which is a wellknown proto-oncogene. Furthermore, $1,25(\mathrm{OH})_{2} \mathrm{D}$ can induce growth arrest, in part through stimulating hypophosphorylation and accumulation of the cyclin-dependent kinase inhibitor $\mathrm{p} 27$ in the nucleus, a process mediated by the PTEN gene. In addition, $1,25(\mathrm{OH})_{2} \mathrm{D}$ increased cell adhesiveness through PTEN-dependent fibronectin upregulation $[5,8]$.

The conflicting results about the effect of vitamin $\mathrm{D}$ on thyroid cancer as well as other cancers, such as colon, breast, and prostate, are in part due to cross-sectional studies with few subjects, the heterogeneity of the study population, seasonal variation in blood sampling, the inter-method analytical variability of vitamin $\mathrm{D}$ assays and conflicting definitions of vitamin D deficiency/insufficiency [4, 23]. Epidemiological studies are simply correlative relationships and they cannot be used to determine cause and effect [4]. It is unclear whether the low $25(\mathrm{OH}) \mathrm{D}$ levels observed in cancer are the result of the cancer or part of its cause [23]. Rather, low vitamin D levels in cancer can be explained by results of low vitamin D intake, malabsorption, lack of sun exposure, or reduced outdoor activity [23]. In addition, it is possible that $25(\mathrm{OH}) \mathrm{D}$ captures other important information about an individual's risk factor profile that is either directly or indirectly associated with health outcomes, because it is well documented that 25(OH)D levels are related to body size, physical activity, genetic background, and skin pigmentation [6]. Because an individual with a lower BMI and higher physical activity is more likely not only to have higher 25(OH)D levels but also to be related to lower cancer risk, it is difficult to separate the effects of these characteristics from those that may be attributed to $25(\mathrm{OH}) \mathrm{D}$ levels [6]. Additionally, because serum vitamin D levels were measured only once, the values obtained might not be representative [19].

The present study has several limitations. Firstly, there is the possibility of selection bias because subjects were selected from the group of patients who visited a tertiary hospital and were sampled. Secondly, this study only investigated cross-sectional data retrospectively. So, the causal relationship between low vitamin D status and cancer could not be determined. Thirdly, there is the lack of healthy controls. Fourthly, sample size is relatively small, especially for thyroid cancer. Fifthly, seasonal variations in blood sampling might have influenced the results, because patient sampling was not performed in a single season. However, the results were not different after the adjustment for season. Sixthly, only patients of Asian ethnicity were included. Lastly, $1,25(\mathrm{OH})_{2} \mathrm{D}$ levels or polymorphism were not obtained.

In conclusion, low vitamin D status was not associated with the development of thyroid cancer and the aggressiveness or prognosis of DTC. Additional randomized, controlled, and prospective studies are needed to investigate whether vitamin $\mathrm{D}$ insufficiency is related to thyroid cancer and is a causal factor in the pathogenesis of thyroid cancer, and whether vitamin $\mathrm{D}$ supplementation would be helpful in patients with these diseases.

\section{Grant Support}

None.

\section{References}

1. Muscogiuri G, Tirabassi G, Bizzaro G, Orio F, Paschou SA, Vryonidou A, Balercia G, et al. Vitamin D and thyroid disease: to D or not to D? Eur J Clin Nutr. 2015;69(3):291-296.

2. Makariou S, Liberopoulos EN, Elisaf M, Challa A. Novel roles of vitamin D in disease: what is new in 2011? Eur J Intern Med. 2011;22(4):355-362.

3. Holick MF. Vitamin D deficiency. N Engl J Med. 2007;357(3):266-281.

4. Plum LA, DeLuca HF. Vitamin D, disease and therapeutic opportunities. Nat Rev Drug Discov. 2010;9(12):941955.

5. Feldman D, Krishnan AV, Swami S, Giovannucci E, Feldman BJ. The role of vitamin D in reducing cancer risk and progression. Nat Rev Cancer. 2014;14(5):342-357.

6. Jacobs ET, Kohler LN, Kunihiro AG, Jurutka PW. Vitamin D and Colorectal, Breast, and Prostate Cancers: A Review of the Epidemiological Evidence. J Cancer. 2016;7(3):232-240.

7. Morand GB, da Silva SD, Hier MP, Alaoui-Jamali MA. Insights into genetic and epigenetic determinants with impact on vitamin d signaling and cancer association studies: the case of thyroid cancer. Front Oncol. 2014;4:309.

8. Clinckspoor I, Verlinden L, Mathieu C, Bouillon R, Verstuyf A, Decallonne B. Vitamin D in thyroid tumorigenesis and development. Prog Histochem Cytochem. 2013;48(2):65-98.

9. Clinckspoor I, Hauben E, Verlinden L, Van den Bruel A, Vanwalleghem L, Vander Poorten V, Delaere P, et al. Altered expression of key players in vitamin D metabolism and signaling in malignant and benign thyroid tumors. $\mathrm{J}$ Histochem Cytochem. 2012;60(7):502-511.

10. Khadzkou K, Buchwald P, Westin G, Dralle H, Akerstrom G, Hellman P. 25-hydroxyvitamin D3 1alpha-hydroxylase and vitamin $\mathrm{D}$ receptor expression in papillary thyroid carcinoma. J Histochem Cytochem. 2006;54(3):355-361.

11. Kmiec P, Sworczak K. Vitamin D in thyroid disorders. Exp Clin Endocrinol Diabetes. 2015;123(7):386-393.

12. Laney N, Meza J, Lyden E, Erickson J, Treude K, Goldner W. The Prevalence of Vitamin D Deficiency Is Similar between Thyroid Nodule and Thyroid Cancer Patients. Int J Endocrinol. 2010;2010:805716.

13. Stepien T, Krupinski R, Sopinski J, Kuzdak K, Komorowski J, Lawnicka H, Stepien H. Decreased 1-25 dihydroxyvitamin D3 concentration in peripheral blood serum of patients with thyroid cancer. Arch Med Res. 2010;41(3):190-194.

14. Jonklaas J, Danielsen M, Wang H. A pilot study of serum selenium, vitamin $\mathrm{D}$, and thyrotropin concentrations in patients with thyroid cancer. Thyroid. 2013;23(9):1079- 
1086.

15. Roskies M, Dolev Y, Caglar D, Hier MP, Mlynarek A, Majdan A, Payne RJ. Vitamin D deficiency as a potentially modifiable risk factor for thyroid cancer. J Otolaryngol Head Neck Surg. 2012;41(3):160-163.

16. Sahin M, Ucan B, Ginis Z, Topaloglu O, Gungunes A, Bozkurt NC, Arslan MS, et al. Vitamin D3 levels and insulin resistance in papillary thyroid cancer patients. Med Oncol. 2013;30(2):589.

17. Kim JR, Kim BH, Kim SM, Oh MY, Kim WJ, Jeon YK, Kim SS, et al. Low serum 25 hydroxyvitamin D is associated with poor clinicopathologic characteristics in female patients with papillary thyroid cancer. Thyroid. 2014;24(11):1618-1624.

18. Haugen BR, Alexander EK, Bible KC, Doherty GM, Mandel SJ, Nikiforov YE, Pacini F, et al. 2015 American Thyroid Association Management Guidelines for Adult Patients with Thyroid Nodules and Differentiated Thyroid Cancer: The American Thyroid Association Guidelines Task Force on Thyroid Nodules and Differentiated Thyroid Cancer. Thyroid. 2016;26(1):1-133.
19. Ahn HY, Chung YJ, Park KY, Cho BY. Serum 25-Hydroxyvitamin D Level Does Not Affect the Aggressiveness and Prognosis of Papillary Thyroid Cancer. Thyroid. 2016;26(3):429-433.

20. Zhang LR, Sawka AM, Adams L, Hatfield N, Hung RJ. Vitamin and mineral supplements and thyroid cancer: a systematic review. Eur J Cancer Prev. 2013;22(2):158168.

21. Penna-Martinez M, Ramos-Lopez E, Stern J, Hinsch N, Hansmann ML, Selkinski I, Grunwald F, et al. Vitamin $D$ receptor polymorphisms in differentiated thyroid carcinoma. Thyroid. 2009;19(6):623-628.

22. Penna-Martinez M, Ramos-Lopez E, Stern J, Kahles H, Hinsch N, Hansmann ML, Selkinski I, et al. Impaired vitamin D activation and association with CYP24A1 haplotypes in differentiated thyroid carcinoma. Thyroid. 2012;22(7):709-716.

23. Mazokopakis EE, Papadomanolaki MG, Tsekouras KC, Evangelopoulos AD, Kotsiris DA, Tzortzinis AA. Is vitamin D related to pathogenesis and treatment of Hashimoto's thyroiditis? Hell J Nucl Med. 2015;18(3):222-227. 